\title{
STEFAN ZWEIG E 0 OLHAR ESTRANGEIRO SOBRE 0 BRASIL E 0 CARNAVAL
}

Maria Elizabeth Chaves de Mello

O texto propõe uma releitura do livro Brasil, um país do futuro, de Stefan Zweig, buscando nele a idealização romântica que inúmeros viajantes estrangeiros têm e sempre tiveram do Brasil. No caso de Stefan Zweig, a discussão mais interessante é a visão do carnaval carioca de 1942, que ele descreve totalmente idealizado, sem nunca o ter visto. [abstract on page 281]

CARNAVAL, BRASIL, STEFAN ZWEIG.

MELLO, Maria Elizabeth Chaves de. Stefan Zweig e o olhar estrangeiro sobre o Brasil e o carnaval. Textos escolhidos de cultura e arte populares, Rio de Janeiro, v.7, n.2, p. 199-206, nov. 2010. 
Sempre, em toda parte, os homens sonharam com terras ideais, países imaginados por filósofos, pensadores, romancistas, pintores, arquitetos e, hoje, cineastas e profissionais da mídia. Durante o Renascimento, Thomas Morus elabora o mito da Utopia, ilha idealizada. É a época das grandes descobertas, da chegada dos europeus nas Américas. Cristóvão Colombo, por ocasião do descobrimento do Novo Mundo, que ele pensava ser o paraíso, supunha que os homens ali teriam a oportunidade de se regenerar, enquanto aguardavam o juízo final. Sérgio Buarque de Holanda (1995) afirma que é nessa perspectiva de regeneração que se deve interpretar a expressão Novo Mundo, conceito que se opõe, desde o início, ao de Velho Mundo, com suas guerras de religião, seus problemas, sua decadência, suas teorias envelhecidas e caducas. Já na carta de Pero Vaz de Caminha, o Brasil é descrito de maneira idealizada, e isso se reproduz, ao longo da história do país, pelos diferentes viajantes que o visitam. Jean de Léry, André Thévet, La Condamine, Francis de Castelnau, Ferdinand Denis descrevem um lugar paradisíaco, livre das opressões da Europa. A leitura desses relatos de viagem contribui ainda mais para a idealização do Brasil na Europa, durante o período romântico.

É o que observamos em Balzac, que, esgotado de cansaço, doente, sentindo-se sem forças para acabar La Comédie Humaine, sonha em ir morar no Brasil, para recomeçar a vida, segundo o texto póstumo de Stefan Zweig:

Pela primeira vez na vida, Balzac tem momentos de desânimo. Pensa seriamente em deixar Paris, a França, a Europa e ir viver no Brasil. Parece que lá existe um imperador Dom Pedro que o salvará e lhe oferecerá um abrigo e lar. Balzac encomenda livros sobre o Brasil, sonha, reflete. Pois sente que isso não pode continuar como está. É preciso que um milagre intervenha para salvá-lo da escravidão inútil, urge que alguma coisa aconteça subitamente, que o libere dos grilhões da sua galera, traga-lhe o descanso, após esse excesso de tensão que ele não aguenta mais (ZWEIG, 1950).

Ora, há muitas motivações para esses sonhos sobre o Brasil, para a construção dessa imagem que torna o país, cada vez mais, o lugar da felicidade, a terra do futuro, dos desejos realizados, o Pays de Cocagne... Em 1868, o conde austríaco Prokesch-Osten, na sua carta a Gobineau, fala do Brasil como: “Um país novo, um porto magnífico, o afastamento da mesquinha Europa, um novo horizonte político, uma terra do futuro e um passado quase desconhecido..." (ZWEIG, 2006, p. 11) Mas nenhum desses olhares foi tão difundido e com tanto apelo quanto o de Stefan Zweig, durante a Segunda Guerra Mundial, com a obra Brasil, um país do futuro.

Em 1936, o escritor judeu austríaco Stefan Zweig visita o Brasil pela primeira vez. A Europa vive, naquele momento, as vésperas da Segunda Guerra Mundial, na qual ele ainda não acredita. Viaja à América do Sul para fazer conferências, cheio de convicções humanistas, pacifistas, internacionalistas, de tolerância política e de convivência social. Seu pacifismo é absoluto, integral e intransigente. Ao chegar, entusiasma-se logo com a acolhida dos brasileiros aos estrangeiros: "Todo recém-chegado é recebido calorosamente, e tudo Ihe é facilitado da maneira mais obsequiosa (...) todos são unânimes em elogiar essa primeira e mais básica característica deste povo: sua boa índole" (Idem, ibidem, 
p. 130). Sucesso total de público, recebido por intelectuais e artistas, ele volta para a Europa com ótima impressão do Brasil, e com a ideia de escrever um livro sobre essa terra tão acolhedora. São tempos difíceis para os judeus na Áustria. Em 1938, seus livros são queimados em Berlim, em praça pública. Stefan Zweig, depois de perder a nacionalidade austríaca e a esperança, amedrontado, pede a nacionalidade britânica, ao mesmo tempo em que solicita ao governo do Brasil (cujo chefe de Estado é o ditador Getúlio Vargas) para ir morar no país que o acolhera tão bem, pouco tempo antes. Em 1941, após um período em Londres e nos Estados Unidos, ele se estabelece no Brasil com a segunda muIher, Lotte (Charlotte Elisabeth Altmann). Não suportando o calor do Rio de Janeiro, eles vão viver em Petrópolis, a mais europeia das cidades dos arredores, tanto pelo seu clima (nas montanhas), quanto pela imigração suíça e alemã. Brasil, um país do futuro, acabara de ser publicado e, graças a essa obra, o autor obtém de Getúlio Vargas o visto de permanência no país. O Brasil aí é aprsentado de maneira bem positiva:

Agora se sabe porque a alma fica tão aliviada logo que pisamos nesta terra. No primeiro momento, tem-se a impressão de que esse efeito liberador e calmante é apenas uma alegria para os olhos, uma absorção feliz daquela beleza única que acolhe o recém-chegado com os braços bem abertos. Logo, no entanto, reconhecemos que essa disposição harmônica da natureza aqui passou a ser o modo de vida de uma nação inteira (Idem, Ibidem, p. 20).

Visão totalmente romântica do Brasil, contando até com a cumplicidade entre a natureza e os sentimentos de um povo inteiro, que corresponderia à paisagem em seus modos e costumes, o livro vai contra o horizonte de expectativas da intelligentsia brasileira, que deseja, naquele momento, textos polêmicos e críticos contra o governo e o que se vive no país. A imagem de um Brasil idealizado, visto como um paraíso, não cai num bom momento. Assim, Zweig é rejeitado e recusado pelo mesmo público que the dera, tanto a ele quanto a sua obra, uma acolhida tão generosa e entusiasta, em 1936. Ofendidos por esse livro que eles consideram vendido, escrito para bajular um ditador de direita, cheio de clichês e de informações erradas sobre o Brasil, intelectuais e artistas se afastam do autor. Muitos o censuram por ter vendido a obra em troca do visto de permanência. Deprimido, isolado em Petrópolis, abalado por ver a Segunda Guerra destruir seus sonhos de humanismo e de Europa pacificada, considerando a cultura europeia perdida (O mundo de ontem - lembranças de um europeu, que ele escreve pouco antes de morrer), Stefan Zweig se suicida com sua mulher Lotte, em 22 de feveriro de 1942, quatro dias depois de ter visto o carnaval brasileiro pela primeira vez na vida.

Na verdade, Brasil, um país do futuro exige uma releitura hoje, e é o que nos propomos fazer, ao tentar verificar em que sentido o imaginário e o real se confundem nessa visão idealizada do Brasil. O livro apresenta o Brasil como tudo o que a Europa não é, como o seu avesso. Segundo Zweig, à morte do Velho Mundo, envenenado por suas próprias teorias racistas, deterministas e violentas, corresponde o futuro proposto pela cultura mestiça brasileira. Esse talvez seja o único caso de um título de livro se tornar epíteto nacional. Um título que faz pensar na Utopia de Thomas Morus, o futuro como símbolo de atemporal, fora da realidade. Como já observamos, o livro tem como principal 
recompensa um visto de permanência no Brasil. Durante a elaboração da obra, Zweig já fugira da Áustria, está na América do Norte, mas prefere ir para o Brasil, o contrário da Europa, tão amada e admirada pelo autor, mas que lhe dá tanto medo. O Brasil, no olhar do autor, aparece como para o conde austríaco Prokesch-Osten, em 1868, em carta a Gobineau: "Um país novo, um porto magnífico, a distância da mesquinha Europa, um novo horizonte político, uma terra do futuro e um passado quase desconhecido..." Desde 1936, ocasião da primeira visita de Zweig, o autor se apaixona pela cultura brasileira, suas festas, sua mestiçagem, sua mistura de melancolia e alegria de viver, fatores que ele considera a única reação possível às catástrofes morais e materiais que deram origem à Segunda Guerra Mundial. O Brasil, segundo ele, significaria a única salvação possível para a humanidade, já que um país voltado para o futuro, virgem das maldições do Velho Mundo...

Para tentar entender essa cultura tão estrangeira para um europeu, Zweig recorre às teorias do clima, raça e meio, ideias oriundas de Montesquieu e de Taine, adaptando-as aos novos tempos e ao novo país que ele acabava de descobrir: "Tudo aquilo que hoje chamamos e reconhecemos como sendo brasileiro não é explicável a partir de uma tradução própria, e sim pela transformação criativa do que já foi europeu pelo país, pelo clima e por sua gente" (Idem, Ibidem, p.128).

O Brasil seria, portanto, uma recriação da Europa, uma adaptação, espécie de laboratório de experiências de suas ideias e teorias em outras terras, miscigenadas com outros povos, outras raças, em outro clima. Parece-lhe que o país inventa uma nova forma de civilização. Essa recriação é confirmada no seu texto sobre a lavagem do Bonfim, na Bahia, quando ele afirma que: "Mas esse é o mistério da Bahia: o fato de que, desde os antepassados, a religão se mistura ao prazer de forma tão misteriosa, em que veIhos ritos africanos cruentos se mesclam de forma curiosa com um fanatismo católico" (ZWEIG, 2006, p. 239).

E ainda: "Por isso, é sobre a existência do Brasil, cujo único desejo é a construção pacífica, que repousam nossas maiores esperanças de uma civilização futura e de pacificação do nosso mundo devastado pelo ódio e pela loucura" (Idem, Ibidem, p. 23).

O carnaval, nessa perspectiva, seria significativo dessa cultura mestiça, sem preocupação, nem com o passado, nem com o futuro. Segundo o autor, no Rio de Janeiro, sufocado pelo forte calor de fevereiro, o carioca faz a sua catarse durante três dias por ano:

Nada mais enganoso do que acreditar que os cariocas fiquem esgotados com o calor: ao contrário, até parece que esse calor acumulado leva a uma explosão dos impulsos que ocorre com regularidade no carnaval. Todo mundo sabe que o carnaval do Rio não tem par no nosso mundo tão obscurecido pela tristeza, em termos de excesso de alegria e entusiasmo. Durante meses, todos poupam e ensaiam, pois cada ano o carnaval traz novos sambas e novas danças. E como o carnaval é uma festa democrática, uma explosão de prazer, uma manifestação de alegria de toda a população, escutam esses sambas já bem antes da festa para que todos saibam cantá-los: nos cassinos, nos restaurantes, no rádio, no gramofone e nos barracos dos negros. Por toda parte há en- 
saios para a grande parada da alegria coletiva. Quando finalmente o calendário permite, os estabelecimentos comerciais fecham por três dias, e é como se a cidade inteira tivesse sido picada por uma tarântula gigantesca. Todos vivem nas ruas, dança-se e canta-se até tarde da noite, e tocam-se todos os tipos imagináveis de instrumentos. Todas as diferenças sociais são abolidas, estranhos caminham abraçados, todos falam com todos, e gradualmente essa animação recíproca se exalta e chega a um tipo de loucura; veem-se pessoas exaustas deitadas nas calçadas sem que tivessem bebido uma só gota de álcool, apenas se extenuaram de tanto dançar e cantar. Mas o mais curioso, o mais tipicamente brasileiro é que, mesmo nesses êxtases, as pessoas, inclusive das camadas mais baixas, não perdem seu espírito de humanidade; apesar da liberdade de usar máscaras, não acontecem brutalidades ou inconveniências, em meio a uma multidão que dança infantilmente. Gritar até não poder mais, dançar até não aguentar mais, poder se livrar mais uma vez de maneira orgiástica da discrição, do comedimento, é como um daqueles temporais de verão. Depois, volta o comportamento tranquilo, a cidade volta à sua ordem. $\mathrm{O}$ verão foi comemorado, as pessoas se libertaram do calor acumulado, o Rio voltou a ser o Rio, a cidade que, calma e orgulhosa, reflete sua própria beleza (Idem, Ibidem, p. 193).

Ora, é preciso esclarecer que, ao escrever esse texto, Stefan Zweig nunca tinha visto o carnaval do Rio. Ouvira falar dele, muitas vezes e de várias maneiras, e esse é o melhor exemplo de como se pode construir um olhar sobre alguma coisa a partir do imaginário. No seu ensaio Histoire ou littérature?, Roland Barthes questiona:

e se a obra fosse exatamente o que o autor não conhece, o que ele não vê? Não precisamos ser psicanalistas para percebermos que um ato (e principalmente um ato literário, que não espera nenhuma sanção da realidade imediata) pode muito bem ser o signo inverso de uma intenção.... a imaginação é deformadora; a atividade poética consiste em desfazer imagens" (BARTHES, 1963, p. 154).

Partindo dessas afirmações barthesianas, poderíamos supor que Zweig constrói a sua utopia sobre o carnaval do Brasil segundo os clichês, que falam de uma festa do exagero, do caos, destinada a quebrar a monotonia do cotidiano e da obediência às normas sociais, quase sempre muito injustas, no caso brasileiro.

Na verdade, naquele momento, ao contrário, o carnaval é muito hierarquizado, cada um tem o seu lugar na festa carioca, como, aliás, ainda ocorre hoje. Em 1942, há o carnaval popular, dos ranchos, das escolas de samba, na Praça XI; os grandes bailes, muito chiques, no Theatro Municipal e nos clubes; os corsos, desfiles dos ricos e poderosos nos seus carros magníficos. $\mathrm{E}$, de fato, na época, o povo ouvia no rádio as marchinhas e os sambas-canções de Ari Barroso, Lamartine Babo, Noel Rosa e Cartola, muitas semanas antes da festa, para aprendê-las. Getúlio logo percebe que poderia tirar proveito da música popular, por seu prestígio junto à população. Assim, as escolas de samba, antes sustentadas apenas pelos comerciantes, passam a ser financiadas pelo governo. Como exemplo, em 1933, a população do Morro do Salgueiro foi ameaçada de ser desalojada. Foi a escola de samba que negociou com Vargas, que, espertamente, permitiu a per- 
manência da comunidade. Em 1937, ele publica um decreto, que obrigava as escolas de samba a só tratar de temas "históricos e patrióticos". Era evidente o uso da manifestação popular para criar uma boa imagem do Estado Novo. Até as letras das músicas são censuradas, como o atestam vários exemplos.

Stefan Zweig não teve, evidentemente, tempo, nem ocasião, de constatar essa realidade, antes de escrever o livro. Ele retorna ao Brasil, pela segunda vez, em 1940, numa turnê de palestras; volta aos Estados Unidos, onde escreve Brasil, um país do futuro, publicado, ao mesmo tempo, no Brasil e em Portugal, em 1941, pouco tempo antes de o autor se instalar definitivamente no país. De qualquer maneira, mesmo sem falar na ditadura, ele percebe que o povo é oprimido e que faz a sua catarse no carnaval. Encontramos sinais, no seu texto, de que o carnaval é visto por ele como uma descarga a uma opressão:

Gritar até não poder mais, dançar até não aguentar mais, poder se livrar mais uma vez de maneira orgiástica da discrição, do comedimento, é como um daqueles temporais de verão. Depois, volta o comportamento tranquilo, a cidade volta à sua ordem (ZWEIG, 2006, p. 193).

Embora não fale explicitamente da ditadura, ele apresenta o carnaval como um momento de compensação do sistema repressivo em que vivem os brasileiros, no início dos anos 40. Seriam três dias de descontração, de liberação, em que o sistema é invertido, em que as regras são abolidas. Finda a festa, tudo volta à ordem, a sociedade retoma seu controle e as leis se instalam novamente. Seria um intervalo, para que o povo, vivendo sob o controle rígido de um regime repressivo, possa aguentar e sobreviver.

É interessante observar, também, nesse texto ficcional, a insistência em falar da cordialidade do brasileiro, sempre equilibrado, sem nunca perder a medida. O livro todo é impregnado dessa ideia, desde a acolhida que o autor tem no país, na primeira vez em que o visita. Ora, esse tema remete a Raízes do Brasil, a tese de Sérgio Buarque de Holanda sobre o homem cordial, a que já nos referimos, que surge em 1936, exatamente quando Zweig desembarca no Brasil pela primeira vez. De uma maneira ou de outra, pelo fato de oferecer um espetáculo em que se misturam mito e realidade, o carnaval imaginado por Stefan Zweig se presta a várias leituras, que vão além do que a interpretação poderia perceber, inicialmente.

Apesar do desconhecimento da realidade brasileira, por falta de vivência dela, ao escrever o livro; apesar, principalmente, das diferentes abordagens dos estudos sobre o carnaval, nos dias de hoje, suscitadas pelo desenvolvimento das pesquisas sobre o mito dessa sociedade cordial, podemos afirmar que as observações de Stefan Zweig muito se aproximam dos estudos de Roberto DaMatta. Carnavais, malandros e heróis (1997) também foi escrito durante uma ditadura no Brasil, a dos militares (1979). Roberto DaMatta constata, no seu livro, que o carnaval cria, na sociedade, um momento igualitário de liberdade total, um clima de igualdade, em que o povo transborda suas emoções, sempre reprimidas. A partir do estudo dessa festa, ele tenta, então, elaborar teorias sobre o brasileiro, em geral. Afirma que haveria uma oscilação, entre momentos de coer- 
ção social intensa e outros de relaxamento, de euforia, num movimento pendular que o autor reconhece na sociedade brasileira. Isso corresponde perfeitamente ao texto de Zweig, em que, finda a festa, o povo volta à rotina da vida cotidiana, pacificado pela catarse realizada.

Quanto ao mito da cordialidde racial, DaMatta denuncia o preconceito mascarado, hipócrita, invisível, sutil, que se esconde sob essa cordialidade. Segundo o antropólogo, durante o carnaval, considera-se que nada do que acontece é sério (DAMATTA, 1997). Por isso é que é permitida a inversão da vida quotidiana. Mas trata-se de uma inversão/ mitificação organizada, elitizada, domesticada. Em 1940, já existe o cortejo disciplinado das escolas de samba, com normas para cada participante, e que rivaliza com outros grupos, até mais organizados, naquele momento, como blocos e ranchos. As próprias escolas de samba têm os seus grupos e são promovidas ou rebaixadas a cada ano, numa classificação rigorosa, com concursos, eliminações, promoções. Trata-se de um sistema muito seletivo, pouco democrático, portanto.

Para DaMatta, na festa carnavalesca, predomina o inesperado, o fato de não se saber o que vai acontecer. A vida burguesa, com suas regras e hipocrisia, é abalada, virada pelo avesso. Mas é preciso colocar ordem na desordem, para que a inversão se realize com sucesso. Zweig também constata isso, em fevereiro de 1942, ao ver o carnaval ao vivo, pela primeira vez, menos de uma semana antes de morrer. Com efeito, é só no final da vida, já muito deprimido, à beira do suicídio, que ele desce de Petrópolis para conhecer o carnaval. Vai assistir ao desfile dos ranchos, na Praça XI, lugar do carnaval dos pobres. Já naquela época, o ponto culminante do carnaval do Rio é o desfile das escolas de samba. 1942 é o ano de "Amélia" e de "Vão acabar com a Praça Onze". Ao saber que as músicas carnavalescas são censuradas, Zweig observa, para o jornalista Silva Reille: "Se, sob o jugo da ditadura, um povo tem o sentido da liberdade tão aguçado, o que acontecerá quando ele tiver o direito de exprimir livremente os seus sentimentos?" (apud DINES, 2004, p. 467). E concebe um plano de escrever outro livro, dessa vez, sobre o carnaval brasileiro, o Elixir da alegria. Convidado para ir ao baile do Municipal, onde se diverte a alta burguesia, ele recusa. Parece-lhe absurdo e paradoxal esse baile, quando a Europa é vítima da pior das guerras, em que tantos sofrem tanto. Aceita e respeita o carnaval como manifestação popular, mas recusa ver o carnaval dos ricos. Até mesmo os corsos o deprimem e ele atravessa esse desfile dos carros dos ricos, sem prestar a menor atenção, no caminho para o terminal do ônibus, que o leva de volta a Petrópolis.

Acabado o carnaval, os jornais anunciam o bombardeio do navio Buarque, pelos nazistas. Cada vez mais deprimido, Zweig teme que a guerra chegue ao paraíso... Iria o Brasil, o país da paz e da mestiçagem, entrar também nessa onda de horror? Quatro dias após o fim do carnaval, em 22 de fevereiro, ele e sua mulher Lotte são encontrados pela empregada, mortos no quarto. Um pacto de suicídio, por depressão, ou por perder toda a esperança de vitória. Sua última carta é, ainda, um hino ao Brasil:

Antes de deixar a vida por minha livre e espontânea vontade e em pleno domínio de minhas faculdades, sinto-me impelido a cumprir uma última obrigação: 
fazer um sincero agradecimento a esta esplêndida terra do Brasil, que proporcionou a mim e ao meu trabalho um repouso tão generoso e hospitaleiro. Meu amor por este país aumentou dia após dia, e em nenhum outro lugar eu teria preferido reconstruir uma vida nova, hoje que o mundo da minha língua desapareceu para mim e que meu lar espiritual, a Europa, destruiu a si mesmo. Mas, depois de 60 anos, é preciso ter uma força incomum para fazer um começo inteiramente novo. A que possuo esgotou-se nos longos anos de perambulação sem teto. Assim, julgo melhor concluir, em tempo hábil e de cabeça erguida, uma vida na qual o trabalho intelectual representou a mais pura alegria, e a liberdade pessoal, o bem mais precioso da Terra. Saúdo todos os meus amigos! Possam eles ter a graça de ainda ver a alvorada depois da longa noite! Eu, impaciente demais, sigo na frente. Stefan Zweig, Petrópolis, 22 de fevereiro de 1942 (apud, BAYLE, s.d.).

Resta-nos observar a sua afirmação sobre a liberdade pessoal ligada ao trabaIho intelectual, uma resposta aos que o acusaram de "vender" o livro em troca do visto. Curiosamente, sua morte se dá no país por ele considerado o último refúgio para os perseguidos do racismo ariano, paraíso da ambivalência, ou país dos contrastes, em precioso equilíbrio, como ele definia o Brasil em seu polêmico Brasil, um País do Futuro. Ou, para citar Alberto Dines, é a morte no paraíso...

\section{BIBLIOGRAFIA}

BARTHES, Roland. Histoire ou littérature? In Sur Racine, Paris: Editions du Seuil, 1963.

BAYLE, Jean-Christophe loubet del. Stefan Zweig au Brésil. http://www.capsurlemonde. org/bresil/zweig.html

DAMATTA, Roberto. Carnavais, malandros e heróis: para uma sociologia do dilema brasileiro. Rio de Janeiro: Rocco, 1997.

DINES, Alberto. Morte no paraíso: a tragédia de Stefan Zweig. Rio de Janeiro: Rocco, 2004.

HOLANDA, Sérgio Buarque. Raízes do Brasil. São Paulo: Companhia das Letras, 1995.

QUEIROZ, Maria Isaura Pereira de. Carnaval brésilien: le vécu et le mythe. Paris: Gallimard, 1992.

ZWEIG, Stefan. Balzac: le roman de sa vie. Paris: Editions Albin Michel, 1950. . Brasil, um país do futuro. Porto Alegre: L\&PM Pocket, 2006.

Maria Elizabeth Chaves de Mello é professora de literatura francesa e comparada do Instituto de Letras da UFF; doutora em letras pela PUC-Rio, pós-doutora pela École des Hautes Etudes en Sciences Sociales, em Paris e pesquisadora PQ1D do CNPq.

Artigo recebido em agosto de 2010 e aceito para publicação em agosto 2010. 